\title{
Reflexiones sobre la titularidad y el título de inter- vención estatal en las infraestructuras públicas
}

\author{
Reflections on the ownership and title of state intervention in \\ public infrastructure
}

\section{Oscar Rafael Aguilar Valdez}

Profesor de Derecho administrativo en las Universidades de Buenos Aires y Católica Argentina. Profesor de posgrado en las Universidades de Buenos Aires, Católica Argentina, Nacional de Tucumán, Nacional del Nordeste, ESAN (Lima, Perú) y Escuela del Cuerpo de Abogados del Estado (Procuración del Tesoro de la Nación). Miembro del Instituto de Derecho administrativo de la Academia Nacional de Derecho y Ciencias Sociales. Presidente de la Comisión de Derecho administrativo del Colegio de Abogados de la Ciudad de Buenos Aires. Socio de Estudio Beccar Varela, Buenos Aires, Argentina. Buenos Aires, Buenos aires, Argentina, e-mail: oaguilar@ebv.com.ar

\section{Resumen}

Tradicionalmente, en el derecho iberoamericano, el régimen de las infraestructuras públicas solía ser enmarcado dentro del régimen del dominio público en tanto éstas se encuentran afectadas a un uso público o a un servicio público en beneficio de la comunidad. En el presente artículo, el autor señala que la imperiosa necesidad de recurrir a fuentes privadas de 
financiamiento ha llevado a tener que admitir la conveniencia de que las infraestructuras públicas puedan ser también titularizadas por el sector privado sin que por ello pierdan su afectación y destinación pública. De esta forma, la finalidad interventora que el Estado perseguiría por medio del régimen dominial podría ser lograda - de igual forma - trasladando el eje del régimen de la noción de "propiedad" a la de "afectación" y, de allí, a su regulación por medio del poder de policía. Se trata, así, de reconocer que esta clase de infraestructuras son "públicas" más que por su "titularidad" por su "destino" o "afectación", siendo esto último lo que verdaderamente justifica el poder de intervención estatal sobre las mismas. En definitiva, sostiene el autor, no se trata de reemplazar al régimen dominial por el poder de policía ni por la regulación, sino de afirmar que todos estos institutos pueden válidamente convivir entre sí e intercambiarse en su aplicación a diferentes bienes e infraestructuras según los también diferentes criterios, formas de financiamiento y finalidades públicas a las que se pretenda recurrir. En ello, tanto la participación pública como la privada resultan imperiosas.

Palabras-clave: Infraestructura. Dominio Público. Concesiones. Financiación de Proyectos.

\section{Abstract}

Traditionally, under Ibero-American law, the public domain regulatory regime was considered the legal framework applicable to public infrastructure as long as these infrastructures are affected to a public interest use or to the provision of public services to the community. In this article, the author points out that the need of private funding has led to having to admit the convenience of private ownership of this kind of infrastructure but without omitting the need of legal safeguards for its public interest destination. Thus, the author sustains that the intervention of the State to guarantee the public interest destination of certain infrastructures could be accomplished - similarly - by moving from the notion of "ownership" to the idea of "affectation to a public use" which authorize Government regulation through the exercise of the Police Power. According to the author, the "public" character of the infrastructures belongs more to its affectation to public uses and destination than to its public ownership. Ultimately, the author affirms, is not about replacing the entire public property regime by the Police Power but asserting that all of these institutes can validly interact or be partly applicable to certain assets or infrastructures depending on the funding source or on the public purposes intended. For this, both private and public participation are compelling.

Keywords: Infrastructure. Public Domain. Concessions. Project Finance. 


\section{Introducción}

Es sabido que las "infraestructuras públicas", es decir, aquellos bienes materiales que sirven de soporte a redes de servicios o de actividades que satisfacen, primordialmente, necesidades de interés público, son, por tal motivo, fundamentales para el desarrollo económico, social y cultural de los países, razón por la cual, desde siempre, fueron objeto de especial atención por el Estado y por el ordenamiento jurídico público. Por su propia naturaleza, éstas suponen una inversión "hundida" en un doble sentido: físico, en tanto suelen ser bienes "fijos" - inclusive muchas de ellas se encuentran "enterradas" - y económico, puesto que son de capital intensivo o sea que requieren tanto importantes desembolsos iniciales como un largo plazo para su amortización. De allí la imperiosa necesidad de costear su construcción y ampliación —en mayor parte- por medio de financiamiento, de forma tal de poder distribuir la carga de soportar su costo a través del tiempo y entre las diferentes generaciones de usuarios que se beneficiarán con la prestación de los servicios públicos y actividades que se brinden con apoyo en las mismas.

En un escenario en el que la inversión en infraestructura y la prestación de servicios públicos recaía casi exclusivamente sobre el Sector Público, el carácter "público" de tales infraestructuras se predicaba no solo de su afectación o destino sino también de su titular, el Estado; ello en tanto que la asociación entre obra pública-dominio público y, en su caso, con el servicio público que se prestaba con asiento en ella, encontraba en el elemento "subjetivo" una clara identidad. De allí pues que, tradicionalmente, fuera el régimen del dominio público el que mejor servía para regular toda la situación jurídica y el aprovechamiento de tales bienes ${ }^{1}$.

\footnotetext{
1 Así, en la doctrina argentina, vid. Marienhoff, 1994, pp. 514 y ss., y Vol. V, pp. 37 y 38; en igual sentido, Barra, 1984, p. 68. La Corte Suprema argentina ha dicho que "[...] para que un bien forme parte del dominio público del Estado, el tribunal ha exigido la consagración real y efectiva al uso público o servicio público [...]"; cfr. in re "Malossi, Noemí Adriana v. E.N.A. - O.N.A.B.E. s/ prescripción adquisitiva", fallo del 15 de julio de 2014, considerando $7^{\circ}$ ). Análoga ha sido la situación en el derecho español; cfr. Jiménez de Cisneros Cid, Francisco, 2000, pp. 45 y ss.; Villar Ezcurra, 2000, pp. 71 y ss.; González Sanfiel, 2000, pp. 151 y ss. En el derecho francés, tradicionalmente se ha entendido que un bien pertenece al dominio público si está afectado a un servicio público, siendo esta la nota relevante, conf. De Laubadére, Gaudemet, 1998, pp. 25, 45, 64 y ss.; Watrin, , 1936, pp. 147 y ss.
} 
Ahora bien, no solo el proceso de privatización y liberalización de servicios públicos llevado a cabo en nuestra región en las últimas décadas sino, fundamentalmente, la imperiosa necesidad de recurrir a fuentes privadas e internacionales de financiamiento para poder llevar a cabo los proyectos de desarrollo de infraestructuras, han puesto en cuestión la conveniencia de mantener esta asimilación y, por lo tanto, ha obligado a replantear la cuestión y, especialmente, a buscar soluciones que permitan, a la par de adecuar su régimen a las exigencias del financiamiento, a garantizar su afectación a las finalidades de interés general que les son consustanciales.

Dentro de tal contexto, y tomando como referencia al caso argentino, nos proponemos efectuar algunas reflexiones sobre las dos cuestiones fundamentales que, en nuestro entender, entraña el régimen jurídico de estas realidades: la determinación de la titularidad de las infraestructuras y del título por medio del cual el Estado puede intervenir en la regulación de su explotación, pretendiendo señalar por qué el régimen del dominio público ya no puede ser considerado el paradigma exclusivo en la materia.

\section{Las infraestructuras públicas y las principales consecuencias de su sometimiento al régimen del dominio público}

Someter a una determinada infraestructura al régimen del dominio público supone, por un lado, asignarle al Estado una verdadera "propiedad" y, por otro, sujetar a la misma a un especial régimen jurídico de protección. Ambas circunstancias, como se verá, no resultan de menor importancia cuando de lo que se trata es de asignarle carácter dominial a las infraestructuras públicas.

Respecto al carácter de verdadera "propiedad" que reviste un bien del dominio público, es decir, una propiedad atribuida a un sujeto de derecho con personalidad jurídica pública (SÁinZ MoRENo, Fernando, 1999, p. 488), cabe recordar que ello encuentra su origen —según se ha dicho- en las ideas medievales (Así, José Luis VILLAR PALASí, 1983, pp. 2379 y ss.) y en la ulterior doctrina francesa, en especial, en la obra de Hauriou para quien el dominio público constituía una propiedad pero de una naturaleza diferente a la privada; se trataba - en sus palabras- 
de una "propiedad administrativa"2. Este criterio de clara atribución subjetiva es el que, con sus matices, ha sido recogido por la mayor parte de los regímenes jurídicos de los países iberoamericanos ${ }^{3}$.

De este carácter "propietarista" del dominio público, no solo se ha derivado una invocada responsabilidad del Estado por los daños causados a terceros por su eventual carácter riesgoso ${ }^{4} \mathrm{o}$ por el defectuoso estado de dichos bienes ${ }^{5}$ así como la posibilidad de que el Estado titular pueda ejercer las acciones reales que le corresponden como "dueño"6, sino también dos consecuencias adicionales que son importantes para el tema en análisis.

En primer lugar, que no existe un dominio público "objetivo", es decir, un régimen que pueda aplicarse a bienes que no se encuentren atribuidos subjetivamente por una norma expresa a la titularidad públi$\mathrm{Ca}^{7}$. Esta circunstancia resulta de relevancia, por cuanto aun cuando estemos en presencia de una infraestructura o de una obra afectadas a una utilidad pública cuya construcción haya sido encomendada por la Administración o costeada con fondos o recursos provenientes de las arcas públicas o extraídos en forma coactiva de la población, la misma no deberá ser considerada per se como integrante del dominio público

2 Así, De Laubadére, Gaudemet, 1998, T. II, p. 29; Parejo Alfonso, pp. 2379 y ss.; GonzÁLEZ GARCíA, 1998, pp. 39 y ss.; HAURIOU (2002, pp. 781 y ss), se manifestaba sobre el carácter de "propiedad" que el Estado tenía sobre los bienes dominiales en razón de las prerrogativas de "propietario" que éste tenía sobre tales bienes las que no podrían entenderse si aquél no fuese un verdadero "dueño" del bien. Sobre la concepción de HAURIOU respecto al dominio público, vid. Sfez, Lucien, 1966, pp. 435 y ss.; y Fernández de Velazco, 1921, pp. 230 y ss.

3 Así, ver las diferentes referencias sobre el régimen dominial vigente en los países iberoamericanos contenidos en González Varas Ibáñez, 2005.

4 Así lo ha resuelto la Corte Suprema de Justicia Argentina, in re "Pose, José Daniel c/ Chubut, Provincia del y otra s/ daños y perjuicios", Fallos 315: 2834. Para una visión crítica de esta jurisprudencia, vid. Perrino, 2005, pp. 138 y ss.

5 Así, también lo tiene afirmado la Corte Suprema Argentina, in re "Cebollero, Antonio Rafael y otros c/ Córdoba, Provincia de s/ daños y perjuicios", Fallos 326: 1910

6 Conf. Marienhoff, 1994, vol. V, pp. 333 y ss.

7 Así, Marienhoff - quien a pesar de considerar que el verdadero titular del dominio público es el "pueblo" - no duda en sostener que "sólo pueden ser titulares del dominio público entidades estatales o comunidades de sustrato típicamente político", ello, debido a que "(...) la titularidad del dominio público apareja delicados privilegios - verbigracia, el ejercicio del poder de policía sobre la cosa pública-, sólo admisibles en el Estado o en sus organismos descentralizados" (conf. MARIENHOFF, Tratado de Derecho administrativo, cit., Vol. V, pp. 84 y ss.). 
si no existe norma expresa que establezca su titularidad estatal8. Amén de que esta solución es la que mejor se adecua con un régimen que reconoce la coexistencia de la propiedad pública y privada en los medios de producción, en tanto que supone una limitación respecto del universo de bienes que pueden ser considerados dominiales, tiene sobrada importancia en materia de financiamiento de infraestructuras públicas.

En segundo lugar, la circunstancia que la titularidad se reconozca en el Estado ha llevado a entender que ella resulta indivisible y que, por lo tanto, no admitiría el menor atisbo de convivencia con la propiedad privada ni con diferentes grados de "dominialidad" pública entre sus partes componentes ${ }^{9}$; lo que no solo dificulta un mejor aprovechamiento económico y funcional de la infraestructura sino que, también, constituye un obstáculo para los mecanismos de financiación de las mismas fundados en instrumentos del derecho privado o de raigambre anglosajona, tradición esta última a la que suelen estar afiliados quienes diseñan tales mecanismos de financiación ${ }^{10}$. Por otra parte, si bien los particulares podrán ser titulares de derechos reales administrativos sobre tales bienes, repárese en que, siendo el Estado el titular indivisible del bien, tales derechos reales administrativos serán verdaderos iura in re aliena $^{11}$, de modo tal que sus titulares no podrán amortizar en sus ba-

8 Hace casi cincuenta años GORDILlo formuló una noción de "obra pública" sosteniendo que "es la cosa mueble o inmueble construida para utilidad o comunidad común que pertenece a una entidad estatal" (cfr. Gordillo, 1966, p. 50). Por otra parte, si —como bien se ha dicho- el dominio público supone una delimitación negativa de la propiedad (cfr. Morillo Velarde Pérez. 2009, p. 125), y tratándose la propiedad privada de un derecho humano esencial reconocido en el ámbito internacional, no puede caber duda alguna que la titularización de un determinado bien por el Estado solo puede tener cabida mediante una ley expresa, único instrumento jurídico que puede limitar derechos individuales.

9 Así, por ejemplo, en la causa "Bergadá Mujica c/ Provincia de Río Negro", Fallos 325: 2223, la Corte Suprema de Justicia de la Argentina sostuvo que: "Cuando el Estado, sobre el terreno de un particular y con consentimiento de este, realiza una obra pública y la entrega al uso de la colectividad, ya no puede mantenerse la distinción entre el terreno - que seguiría siendo del dominio particular y regido por el Código Civil- y la obra - perteneciente al público y ajena al régimen de dicho código-. Se trata en delante de un bien material y jurídicamente indivisible, sujeto a un mismo régimen legal, como bien del dominio público, está fuera del comercio del derecho privado y no cabe a su respecto el ejercicio de acciones reales". En igual sentido, Marienhoff, cit., Vol. V, pp. 102 y ss. En este sentido, vid. Mairal, Héctor, 2005, pp. 131 y ss.

11 La circunstancia que la creación de la teoría de los derechos reales administrativos sea atribuida a Hauriou demuestra que se trata de una construcción efectuada a partir de la existencia de una verdadera "propiedad" en cabeza de un tercero - la Administración Pública-; sobre el particular, conf. el "Préface" de Hauriou a la conocida obra de Rigaud, 1914, pp. v y ss. 
lances como bienes de uso a tales infraestructuras ${ }^{12}$ sino solo a las inversiones hechas al amparo de tales derechos reales administrativos bajo el régimen de activos "intangibles", lo que reviste relevancia a los efectos contables e impositivos ${ }^{13}$.

En lo que hace al régimen jurídico peculiar que emana del carácter dominical, resulta claro que la consecuencia más relevante está dada por la aplicación de la regla de la "inalienabilidad" de los bienes del dominio público ${ }^{14}$ en función de la cual - fruto de considerarse al bien fuera del ámbito del tráfico jurídico de derecho privado-impone serias restricciones a su embargabilidad ${ }^{15} \mathrm{y}$ en la posibilidad de constituir garantías de derecho privado a favor de terceros sobre las mismas ${ }^{16}$. Esta circunstancia, unida a la necesidad de encontrar mecanismos aptos para favorecer el financiamiento de emprendimientos de infraestructura pública ${ }^{17}$, llevó a que la doctrina se ocupara con mayor atención de

12 Ello en tanto que para poder hacerlo, debería ser titular - a título de dueño- del pertinente activo, conf. García Novoa, 1994, p. 123.

13 Conf. García Novoa, cit., pp. 102 y ss. Sobre el particular, téngase en cuenta que la Corte Suprema de Justicia de la Argentina, en el caso "Bourdié, Pedro Emilio v. Municipalidad de la Capital", Fallos 145: 325, reconoció que los derechos que emergían de una concesión de uso de un bien dominical constituían una verdadera "propiedad" garantizada por la Constitución Nacional; de modo tal que el derecho real administrativo constituye un activo intangible cuyo plazo de amortización dependerá del tiempo durante el cual se haya concedido el ejercicio del mismo o del de la vida útil del bien considerada desde el punto de vista económico; en este último sentido se ha pronunciado la Corte Suprema argentina en el caso "Oleoductos del Valle S.A. (TF 19.260-I) c/DGI", causa O. 125. XLIII. R.O, fallada el 16 de febrero de 2010.

14 Sobre la inalienabilidad del dominio público, vid. García de Enterría, 1998; y Clavero Arévalo, 1992.

15 En un caso en donde se había dispuesto la traba de un embargo sobre la infraestructura portuaria en garantía del pago de créditos de particulares, la Corte Suprema de la Argentina dijo: “Que no es preciso un mayor examen para advertir que el acto en cuestión tuvo por finalidad dar en concesión bienes de titularidad estatal que, por hallarse afectados al uso público (art. 2340ㅇ, inc. 7 del Código Civil, arts. $2 \circ, 11$ y $12 \circ$ de la Ley 24.093 , art. 1으, apartado 3, del pliego de condiciones aprobado por la citada resolución 622 de 1996; y Fallos 301: 292), no eran susceptibles de una afectación ulterior en garantía específica del pago de deudas particulares (Fallos 33: 116; 129: 145; 131: 267 y 182: 375, entre otros); carácter que tornaba irrelevante el hecho de que la demandada hubiera consentido la medida cautelar previamente dictada, de acuerdo con el art. 220 del Código Procesal Civil y Comercial de la Nación" (cfr. in re "Díaz, Gustavo Marcelo y otros v. Poder Ejecutivo Nacional - Ministerio de Obras y Servicios Públicos - Secretaría de Transporte", Fallos 320: 1003, considerando 5).

16 En este sentido, vid. De Laubadére, 1975, T. II, p. 170.

17 En Francia, se ha juzgado que el régimen del dominio público -especialmente, por el régimen de la inalienabilidad- desfavorecía la financiación de proyectos de infraestructuras públicas, conf. Ligniéres, 2005 , pp. 249 y ss. 
los ya mencionados derechos reales administrativos ${ }^{18}$ — cuya admisión no importa vulnerar la regla de la inalienabilidad ${ }^{19}-$ y en función de ellos se implementasen mecanismos de garantía que reconocen al derecho real administrativo como activo subyacente de los mismos - p. ej, la cesión fiduciaria del derecho de cobro de peajes y tarifas o el step in de los acreedores sobre la concesión-20. No obstante, cabe señalar que si bien en países como Francia ${ }^{21}$ y España ${ }^{22}$ el recurso a los derechos reales administrativos parece haber sido una solución eficaz para las exigencias del financiamiento, en países como la Argentina en donde no existe - a diferencia de los casos europeos mencionados - una experiencia abonada en su utilización, el recurso a tales derechos reales administrativos en materia de financiamiento ha sido limitada a los dos supuestos ya citados — cesión fiduciaria y step in - o bien, ha sido criticado y desaconsejado 23 .

Evidentemente, las circunstancias apuntadas, en especial, la poca flexibilidad del régimen dominial, conspiraban con la elaboración de un marco jurídico que pudiera resultar de aplicación a procesos de liberalización y de privatización "plena" de infraestructuras y servicios públicos, especialmente si lo que se buscaba era trasladar al sector privado la carga de la incorporación de nuevas infraestructuras y, especialmente, la de su financiación.

De allí, entonces que los procesos recientes tendientes a establecer nuevas fórmulas de asociación entre los sectores públicos y privados para el desarrollo de infraestructuras, imperiosamente exigentes de garantizar eficazmente su financiamiento, haya llevado a la doctrina a

18 Sobre la admisión de los “derechos reales en Argentina, conf. Fanelli Evans, 1996, pp. 93 y ss.; Guiridlian Larosa,, 2004, pp. 338 y ss.; De Reina Tartiére, Gabriel, “La teoría de los derechos reales administrativos: vigencia y aplicación en el derecho argentino", en El Derecho -Administrativo- 2006: 727 y ss.; Boqué, 1998-B, pp. 169 y ss., y Boqué, 2007, pp. 649 y ss. En este sentido, conf. De Laubadére, 1975, cit., T. II, p. 170.

20 Nos hemos referido a estos mecanismos en Aguilar Valdez, 2008 y Aguillar Valdez, 2007.

21 Así, vid. Marcou, , 2000.

22 Para una visión de conjunto de la situación en el derecho español, vid. Fernández Acevedo, 2009, pp. 341 y ss.

23 Así, por ejemplo, en la doctrina argentina, López del Carril, Gonzalo, "Motivos por los que no se pueden aplicar los derechos reales administrativos para generar confianza en los inversores", en LL 2003-F-1486. 
buscar mecanismos que permitan superar las limitaciones que impone la dominialidad pública en esta materia ${ }^{24}$.

\section{El financiamiento privado como exigente de la titularidad privada de infraestructuras públicas}

Frente al panorama descrito, la imperiosa necesidad de recurrir a fuentes privadas de financiamiento ha llevado a tener que admitir la conveniencia de que las infraestructuras públicas puedan ser también titularizadas por el Sector Privado sin que por ello pierdan su afectación y destinación pública.

Si bien — desde el punto de vista jurídico-conceptual- podría sostenerse que la naturaleza pública o privada de la fuente de financiamiento no prejuzgaría sobre la titularidad de las infraestructuras, se ha apuntado que "la obra es de quien la financia y construye, de quien la paga y hace posible, así lo demanda la Justicia. Y cuando se vulnera esta regla elemental no se puede esperar que los factores sociales aporten capitales para el desarrollo social: queda solo la coacción y emerge de nuevo el recurso a la fuerza, a la captación imperativa de dinero, a la supremacía jerárquica de la organización administrativa de la que, de un modo u otro, el contratista o el gestor privado es mero apéndice" 25 . En esta línea, también se ha dicho que “(...) No puede pretenderse que, cuando concurren otros sujetos con sus recursos financieros y empresariales, se obtenga un resultado final idéntico a cuando es la Administración la que sufraga por completo a sus expensas la inversión llevada a cabo (...)"26.

De esta forma, se ha admitido la existencia de infraestructuras públicas de propiedad privada, cuando menos, hasta tanto el financiamiento haya sido amortizado. Así, por ejemplo, en Francia se ha admitido legislativamente que el Estado recurra a operaciones de bail emphyteótique o "censo enfitéutico" para la provisión de infraestructuras

\footnotetext{
24 La cuestión ha sido de especial tratamiento en el derecho español, así vid. Ariño Ortiz, 2000, pp. 38 y ss.; Jiménez de Cisneros Cid, cit., pp. 59 y ss.; Villar Ezcurra, cit., pp. 78 y ss.; González Sanfiel, 2000, pp. 182 y ss.; De la Cuétara Martínez, 2000, pp. 223 y ss.; Jiménez de Cisneros Cid, 1998, pp. 303 y ss.; González Sanfiel, 2000, pp. 243 y ss.; Moreu Carbonell, 2003, pp. 435 y ss.; González García, 2000, pp. 351 y ss.

25 Morell Ocaña, cit., p. 12.

26 RUIZ OJEDA, Alberto, 1999, p. 22 y ss.
} 
públicas a favor de comunidades locales ${ }^{27}$ así como a la realización de operaciones de leasing a favor de entidades nacionales ${ }^{28}$ para la provisión de infraestructuras tales como las hospitalarias ${ }^{29}$, supuestos todos estos en los que, pendiente el período de amortización, los bienes no pertenecen a la Administración ${ }^{30}$.

En Argentina, en concordancia con lo ocurrido en otros países iberoamericanos ${ }^{31}$, el recurso al leasing o a la propiedad fiduciaria se ha transformado en un mecanismo usual para supuestos tales como establecimientos carcelarios ${ }^{32}$ e infraestructuras económicas como las rela-

27 Conf. Ley de 5 de enero de 1988, cfr. Marcou, cit., p. 71; Barcelona Llop, 1995, pp. 564 y ss.

28 Conf. Ley de 25 de julio de 1994, modificatoria del Código del Dominio del Estado, cfr. Subrá de Bieusses, op. y pp. cit.

29 Conf. Ley de 9 de agosto de 2004, cfr. Ligniéres, Paul y Ratledge, Simon, "PPP in France - Healthcare Sector", Linklaters Special Report, 1/10/2004.

30 En lo que respecta al régimen del bail emphyteótique del derecho francés, cabe señalar que se ha dicho que: “(...) Estas disposiciones sirven para modificar de forma importante las relaciones entre la Administración concedente y el concesionario del servicio público si éste obtiene un censo enfitéuti$\mathrm{co}$, ya que el censo evita que las obras realizadas por el concesionario se incorporen inmediatamente al dominio público, como por regla general establecen los pliegos de cláusulas. Dicho de otro modo, estas obras no pasarán a ser propiedad de la Administración Local hasta el término del censo cuando esta vuelva a tomar posesión del bien dado en censo" (cfr. Marcou, cit., p. 72). Por su parte, Subrá de Bieusses (cit., p. 1179) señala, respecto a la Ley del año 1994, que al fin de la operación “(...) los bienes se transforman de pleno derecho y gratuitamente en propiedad del Estado (...)". Sobre el particular, también, Brisson, 2005, pp. 591 y ss.

31 Conf. Malagón, México, 2002.

32 Así, por ejemplo, Licitación Pública Nacional e Internacional № 01/97, convocada por Decreto № 1658 del 27 de diciembre de 1996 para la contratación de la elaboración del proyecto y la construcción de un establecimiento carcelario por el sistema "Ilave en mano", financiados íntegramente por el contratista a su solo riesgo, a ejecutar en predios que a tal efecto, el Estado Nacional transmitirá en dominio fiduciario en la localidad de Ezeiza, Provincia de Buenos Aires; y el ulterior alquiler con opción de compra de dichos inmuebles, a favor del Estado Nacional para su afectación al uso del Servicio Penitenciario Federal; adjudicada en favor de la Unión Transitoria de Empresas conformada por "Techint S.A.C.I., Hochtief A.G., Impregilo S.p.A., Iglys S.A.", dispuesta por Resolución M.D. № 211 del 11 de febrero de 1998 y aprobada por Decreto 203/1998. 
tivas al gas natural ${ }^{33}$, casos todos estos en los que el Estado difícilmente pueda ser considerado un verdadero "propietario", cuando menos, pendiente la vigencia de tales estructuras negociales ${ }^{34}$.

En esta línea, aprovechando la experiencia internacional, el régimen de Asociación Pública Privada vigente en la Argentina para el orden federal cuya finalidad primordial está dada en facilitar el financiamiento de infraestructura, expresamente establece que la propiedad de la obra que se construya a su amparo pasará al dominio estatal solo una vez concluida la vigencia del contrato asociativo ${ }^{35}$. Asimismo, y partiendo de su reconocimiento como bienes de propiedad particular, las licencias otorgadas hace ya más de dos décadas por el Gobierno argentino para la prestación de los servicios de transporte y distribución de gas natural expresamente contemplan que el licenciatario grave los bienes incorporados al Sistema de Gaseoductos y a la red de distribución después de la toma de posesión, siempre que tales gravámenes se constituyan para garantizar créditos a más de un año de plazo tomados para financiar ampliaciones y mejoras del servicio ${ }^{36}$.

Sin lugar a dudas, estos regímenes parten del presupuesto que los financistas - en rigor, los mercados de capitales que son quienes brindan sus fondos a estos proyectos- estarán más propensos a otorgar mejores créditos allí donde tengan certeza sobre los alcances del dere-

33 Así, Carta de intención suscripta el 15 de noviembre de 2004 por los Ministerios de Planificación Federal, Inversión Pública y Servicios y de Economía y Producción, el Banco de la Nación Argentina, la Secretaría de Energía, Nación Fideicomisos S.A., Yacimientos Petrolíferos Fiscales S.A. y Transportadora de Gas del Norte S.A., en relación con la implementación y constitución de Fideicomisos de Gas que contribuyan a aumentar la capacidad de transporte firme a partir de la temporada invernal del año 2005, aprobada por Decreto 1882/2004, en cuya cláusula 10.4. "Bienes fideicomitidos", se dispone que: "Los activos resultantes de la ejecución de las obras de Ampliación del Fideicomiso de Gas conformarán parte del patrimonio del Fideicomiso de Garantía como Bienes Fideicomitidos hasta la cancelación total del Fideicomiso de Gas. Ocurrida tal cancelación, el Fiduciario proveerá la transferencia de la propiedad de dicho Activo Esencial al patrimonio del Fideicomisario".

34 Sobre el régimen del fideicomiso aplicable en materia de infraestructuras públicas en Argentina, vid. Mertehikián, 2005, pp. 539 y ss. y Guiridlian Larosa, Javier, “El Fideicomiso Público como técnica de financiación contractual administrativa", en ED -Administrativo- 2003-546.

35 Así, dispone el último párrafo del artículo 20 del Decreto 967/2005: “En los casos de ejecución de obra pública, al término de la Asociación Público-Privada respectiva, la propiedad de la obra corresponderá al Estado".

36 Cláusula 5.5. de las respectivas licencias. Esta regulación fue, en su momento, criticada por cierta doctrina, cfr. Salomoni, 1996, pp. 302 y ss. y Salomoni, 1999, pp. 359 y ss. Por lo contrario, una defensa de esta regulación puede verse en Tawil, 2005, p. 536. 
cho de propiedad privada de las infraestructuras que si estas se encuentran dentro del dominio público. Si bien con las limitaciones que como se verá más adelante- se derivan de la afectación de las mismas a una finalidad pública, lo cierto es que reconocer su propiedad privada permitirá mejorar el perfil de las garantías que podrán ser otorgadas en respaldo del repago de los préstamos y así abaratar el costo financiero que, en definitiva, debe redundar en tarifas y precios más bajos para los usuarios ${ }^{37}$.

\section{El régimen dominial y el título de intervención en las infraestruc- turas públicas}

Frente a la tesis que fundada en el carácter "propietarista" hace del bien dominial una verdadera "propiedad pública", existe otra concepción que entiende que el dominio público, más que una "propiedad", constituye un título de intervención pública en la vida económica y social 38 .

El principal exponente de esta postura ha sido, sin lugar a dudas, Villar Palasí quien, con fundamento en un erudito análisis histórico, ha apuntado — refiriéndose al dominio público- que con "la creación de estas regalías (...) no se pretende otra cosa sino crear el título de potestad más que incorporar al patrimonio estatal los bienes afectos" 39 . Esta línea ha sido seguida, por ejemplo, por Parejo Alfonso para quien el dominio público no es "algo dado" sino que es algo sustancialmente "dinámico" cuya consistencia viene dada en función de los cometidos propios del poder público en los que se expresan las necesidades y las

37 Téngase en cuenta, además, que a diferencia de lo que ocurre con los bienes del dominio público, en estos casos el propietario podría amortizar en sus libros como bien de uso a tales infraestructuras. En este sentido, ha dicho la jurisprudencia argentina que “(...) conceptualmente un bien lo amortiza quien lo adquirió o financió su construcción (...)", CNFed. Cont. Adm., Sala V, in re "Camuzzi Gas Pampeana S.A. v. Enargas - Resol. 77/95", del 21/10/1996, en especial, considerando IV.

38 En la doctrina argentina se ha dicho que ambas posturas -la que considera al dominio público una "propiedad" y la que lo considera un "título de intervención"- en modo alguno serían inconciliables sino que la figura del dominio público sólo encontraría una acababa explicación en tanto se yuxtapongan ambas miradas, de modo de reconocer al Estado como el verdadero dueño de los bienes que integran la categoría, atribuyéndole, al propio tiempo, la facultad de ejercer aquellas potestades públicas que le competen sobre esos mismos bienes; cfr. Cassagne, 2014, pp. 806-807.

39 Villar Palasí, cit., p. 139 
aspiraciones sociales ${ }^{40}$. En Argentina, se ha enfatizado que, desde la perspectiva constitucional, el régimen del dominio público ha sido concebido, sustancialmente, como un título de intervención, de forma tal que "los bienes públicos en la República Argentina, no constituyen una categoría estática sino un concepto subordinado a actividades que son necesarias satisfacer: el progreso y prosperidad de la Nación a través de la disposición y uso del dominio, entre otras actividades (...)" 41 .

Así, parecería que someter a una determinada infraestructura al régimen del dominio público, antes que perseguir incorporar un activo físico al patrimonio estatal, le permitiría al Sector Público contar con un título específico de intervención en la actividad que se brinda con soporte en ella de forma de lograr, de mejor manera, el interés general. De esta forma, por medio de esta concepción, el régimen dominial se independizaría de la titularidad estatal del bien — que, como vimos, supone una limitación a la aplicación del régimen dominial- para transformarse en un régimen "objetivo" o "virtual" 42 aplicable a infraestructuras de titularidad privada. Así, el titular o explotador de la infraestructura privada estaría sujeto a "cargas de dominio público" que legitimaría a la Administración a ejercer sobre tales bienes privados ciertas prerrogativas clásicas que ésta tiene sobre los bienes públicos ${ }^{43}$.

Si bien se trata de una tesis seriamente esbozada, en nuestra opinión, la misma de modo alguno es apta (i) para fundar una aplicación "expansiva" de la dominialidad pública ni (ii) para excluir la existencia de infraestructuras públicas de titularidad privada sometidas a potestades estatales suficientes - bien que de una naturaleza diferente a las dominiales- que aseguren las finalidades de interés público a las que éstas están llamadas.

Veamos a continuación ambas cuestiones.

Considerar al dominio público como un título de intervención, en rigor, no funda una concepción amplia de la dominialidad pública sino que, por el contrario, puede justificar una aplicación restringida de este instituto. A estos fines, cabe recordar lo dicho antes en punto a que si la titularidad estatal es un elemento tipificante del régimen del dominio

\footnotetext{
40 Parejo Alfonso, cit., p. 2404.

41 Conf. Salomoni, 2000, pp. 100 y ss., en especial, p. 102.

42 Sobre el particular, pero con sentido crítico, conf. Ligniéres, cit., p. 251.

43 Así, Moreu Carbonell, cit., p. 466
} 
público, no es posible sostener la existencia de un régimen dominial de carácter "objetivo" o "virtual" desligado de dicha titularidad pública. Por otro lado, cabe tener en cuenta que por razones históricas - y luego de un proceso secular por cierto complejo- la idea basal del dominio público se ha asentado en la noción de "afectación"44, de modo tal de ser esta el vehículo por medio del cual determinados bienes son colocados bajo el régimen jurídico del dominio público ${ }^{45}$.

Ahora bien, nada hay en la "naturaleza" del régimen dominial que impida que dicha "afectación" - y por lo tanto, la "dominialidad" de un bien determinado - tenga diferentes "grados" según la vinculación que las diferentes partes o segmentos del mismo tengan en relación con el interés público perseguido, o bien que su dominialización quede limitada, exclusivamente, a aquellas partes del mismo que sean las necesarias para garantizar los fines de "intervención" que se dicen perseguir por medio de este instituto, de forma tal que, por ejemplo, ciertas partes de un mismo bien estén sujetas a la dominialidad y las restantes lo estén al dominio privado estatal o, lisa y llanamente, al de las personas particulares.

Respecto de la primer alternativa planteada - establecimiento de diferentes "grados" de dominialidad según la relación que diferentes partes de un mismo bien tengan con el interés público, con la consecuente imposición de diferentes limitaciones a su utilización y/o disposición o al contenido y alcance de los pertinentes derechos reales administrativos que podrían constituirse sobre tales partes, así como la admisión de diferentes afectaciones acumulativas sobre el mismo-, cabe

44 Así, Hauriou, cit., p. 789: “(...) Toda la dominialidad pública reposa sobre la idea de afectación administrativa de cosas a la utilidad pública (...)”. Por su parte, García de Enterría (cit., p. 104) tiene dicho sobre el particular que: “(...) Toda la institución del dominio público gira sobre un criterium esencial: la llamada afectación, destinación, destino, de las cosas particulares que integran sus dependencias (...)”. En similar sentido, Clavero Arévalo, 1992, p. 395 y las citas de doctrina que se invocan en p. 394.

45 Conf. Santamaría Pastor, 1999, Vol. II, pp. 516 y 517. En similar sentido, dice Parejo Alfonso (cit., p. 2418) que se trata del “(...) mecanismo específico por virtud del cual la cosa en sentido jurídicomaterial pasa a quedar sujeta al estatuto o régimen jurídico-público propio de la dominialidad". Esta ha sido, también, la postura tradicionalmente aceptada por la jurisprudencia de la Corte Suprema de Justicia de la Argentina, conf. in re "Don Enrique Alió, por la Provincia de Buenos Aires v. Mar del Plata Golf Club sobre reivindicación", Fallos 146: 305; idem in re "Bergadá Mujica, Héctor c/ Río Negro, Provincia de s/ reivindicación de inmueble", Fallos 325: 2223, con remisión a Fallos 239: 129 y sus citas. 
señalar que esta es una de las posibilidades que han sido objeto de tratamiento reciente tanto por parte de la doctrina francesa ${ }^{46}$ como de la italiana ${ }^{47}$.

En efecto, la realidad demuestra que, aun tratándose de un mismo bien, porciones del mismo pueden tener diferentes grados de afectación a una finalidad pública o al uso público que ameritan la aplicación de regímenes jurídicos parcialmente diferenciados. Tal es lo que ocurre, por ejemplo, con las infraestructuras viales en donde se puede distinguir entre la vía de tránsito propiamente dicha — afectada a la circulación automotor-y las llamadas "áreas de servicios" que el concesionario vial puede explotar en forma comercial y, por ende, sujetas a un régimen jurídico claramente diferenciado del que rige a la vía de tránsito ${ }^{48}$. Idénticas consideraciones caben, por ejemplo, para otras infraestructuras públicas como los aeropuertos, donde con claridad puede advertirse que diversas porciones de una misma realidad física pueden ser escindidas en vistas de su diferente afectación al uso público — por ejemplo, las pistas de aterrizaje y maniobras y los espacios internos de la terminal afectados a la explotación comercial—49. Esta alternativa habilita, por ejemplo, a constituir ciertas garantías reales sobre partes de un bien que tienen menor vinculación con su afectación a la finalidad pública relevante que justifica la dominialidad, favoreciéndose el financiamiento global del emprendimiento infraestructural.

Respecto de la segunda alternativa -limitación de la dominialidad exclusivamente a la porción del bien afectado a la finalidad pública relevante, sometiendo las restantes al dominio privado estatal ${ }^{50} \mathrm{o}$ lisa y llanamente, al de las personas privadas que lo exploten - cabe señalar que ciertos autores han propugnado una reducción de la calificación

46 Sobre el particular, vid. Melleray, 2004, pp. 287 y ss.; Debbasch et al, 1999, p. 108.

47 Vid. Olivi, 2005, pp. 307 y ss.

48 Esto en la Argentina ha sido reconocido en el contrato de concesión de obra pública otorgado bajo el régimen del Decreto 425/2003, Cláusula Decimoprimera, "Áreas de Servicios".

49 Así, en Argentina, el numeral 6.3.3. del Contrato de Concesión del Sistema Nacional de Aeropuertos, dispone -en lo que aquí interesa - que el "uso de los bienes deberá satisfacer plenamente las necesidades del servicio aeroportuario. Podrán también ser utilizados en forma simultánea para otras actividades afines a la actividad aeroportuaria, pero sin que ello pueda afectar el objeto del presente Contrato de Concesión (...)". Análogas consideraciones caben, por ejemplo, para las instalaciones afectadas a un uso comercial en las estaciones de subterráneos o ferroviarias que también están sujetas a un régimen jurídico diferenciado.

50 Tal como lo menciona Mairal cit., pp. 108 y ss.) en base a la experiencia francesa reciente. 
demanial a lo estrictamente necesario por su unión inescindible con la actividad que justifica su afectación, admitiendo que las instalaciones remanentes puedan ser explotadas en régimen de derecho privado, con carácter comercial, en régimen de competencia, puesto que “(...) carece de sentido que la propia Administración sea quien ejerza el papel de dominus en la explotación de unas actividades que nada tienen que ver con sus funciones (...)" 51 .

Desde otra perspectiva, debe advertirse que es una realidad que las diversas infraestructuras públicas -especialmente aquellas que sirven de soporte a servicios que han sido objeto de liberalizacióncompiten entre sí con independencia de la titularidad y/o gestión pública o privada de las mismas ${ }^{52}$. Esta circunstancia - apertura a la competencia y, por ende, sujeción a las reglas de defensa de la misma ${ }^{53}$ - clama por la aplicación de un régimen del que no se deriven situaciones asimétricas que permitan distorsionar las reglas de funcionamiento competitivo. De allí, entonces, que el régimen de la dominialidad — que solo resultaría de aplicación cuando la infraestructura pertenece a la titularidad pública - no solo debiera quedar limitado al "núcleo duro" del mismo - garantía de su concreta afectación - sino que, además, debiera ser reformulado a fin de coordinarlo con la aplicación de las reglas de la competencia ${ }^{54}$.

En adición a estos planteos, tal como ya lo hemos anticipado, entendemos que la tesis que hace del régimen dominial un título de intervención económica, de modo alguno excluye la posibilidad de admitir infraestructuras públicas de titularidad privada pero sometidas a potes-

51 Conf. Ariño Ortiz, cit., pp. 42 y 43.

52 Conf. De la Cuétara Martínez, cit., pp. 223 y ss.

53 A estos efectos, téngase en cuenta que en Argentina el artículo 3o de la Ley 25.156 de Defensa de la Competencia, dispone - en lo que aquí interesa - que quedan "sometidas a las disposiciones de esta ley todas las personas físicas o jurídicas públicas o privadas, con o sin fines de lucro que realicen actividades económicas en todo o en parte del territorio nacional, y las que realicen actividades económicas fuera del país, en la medida en que sus actos, actividades o acuerdos puedan producir efectos en el mercado nacional" (la cursiva nos pertenece).

54 En este sentido, vid. Lavialle, 2004, p. 279, quien cita a jurisprudencia del Consejo de Estado que con razón, según afirma este autor - ha considerado que los actos de gestión dominial, en la medida en que concierna a actividades económicas de mercado, deben respetar las reglas de la competencia. Asimismo, señala el autor que, en particular, aquellas infraestructuras que resultan necesarias para el acceso a un mercado donde se desenvuelven actividades económicas importantes no pueden estar sujetas a reglas diferentes de aquellas en vigor en los otros mercados. 
tades de regulación y control por parte del Estado de naturaleza diferente a las dominiales. El sometimiento de tales bienes a un uso público, abierto y no discriminatorio - finalidad primordial del sometimiento de los bienes al régimen del dominio público- bien puede ser eficazmente garantizado mediante las prerrogativas que se le reconocen a la Administración en materia de regulación de acceso abierto ${ }^{55}$ y de "facilidades esenciales" 56 sin que para ello resulte necesario estatizar la propiedad de tales infraestructuras ${ }^{57}$.

En efecto, de modo análogo a lo que se ha sostenido respecto del "servicio público", aquí también puede decirse que para validar la intervención administrativa en el ámbito económico y social no se requiere otorgar al título de intervención carácter patrimonial alguno ${ }^{58}$, puesto que como también se ha señalado, para regular y controlar no se necesita ser "dueño" 0 . De esta forma, bien puede distinguirse entre la titularidad de la potestad de intervención que pertenece de iure propio al Estado, de la titularidad patrimonial o "propiedad" de determinado bien o "activo" que, pudiendo ser tanto pública como privada, en rigor en nada debería afectar la validez del ejercicio de la mencionada potestad regulatoria.

Debe repararse en que reconocer al Estado la prerrogativa de ejercer el llamado "poder de policía dominial" — cuya naturaleza y alcances son por cierto controvertidos y dudosos-, en rigor, nada agrega en esta materia. Así, en la doctrina argentina Marienhoff ha señalado que la policía del dominio público se trata de una manifestación del "poder general de policía del Estado"60. En igual línea, la doctrina fran-

55 Conf. Hamilton, 2000, p. 46, inter alia.

56 Conf. Pitofsky, Patterson, and Hooks, Johnattan, 2002, p. 443; Lipsky, Sidak, Gregory, 1999, p. 1187; Villar Rojas, 2004.

57 Tal estatización puede tener lugar no solo mediante su sometimiento expreso al régimen del dominio público, sino, también, mediante una aplicación excesiva del principio de open access, provocando, en la práctica, una socialización de la infraestructura sin previa expropiación y compensación, conf. Tribunal de Justicia de la Comunidad Europea, in re "Bronner", 1998; sobre el particular, vid. Downie, McGregor, 2000, pp. 19 y ss.; y Thierer, Wayne Crews Jr., 2003.

58 Así, Cassagne (2006, Vol. II, pp. 292 y ss.) ha sostenido respecto a la publicatio del servicio público que: "Esa titularidad no implica que el Estado actúa a título de dueño sino como titular de la regulación del servicio público que constituye, en algunos sistemas como ocurre actualmente en el nuestro, una actividad de gestión privada y sólo subsidiariamente estatal".

59 Comadira, Julio Rodolfo, "La experiencia regulatoria argentina”, en http://www.ElDial.com.ar.

60 Marienhoff, cit., Vol. V, p. 327. 
cesa ha entendido que la "policía de conservación", en rigor, carece de todo contenido patrimonial y se vincula con la protección de su afectación ${ }^{61}$; agregándose, que las facultades "señoriales" del Estado sobre el dominio público, en principio, solo pueden referirse a actos de "gestión interna" que nunca pueden ser oponibles a terceros ajenos a la Administración, en especial, a aquellos que hacen "utilización" de los bienes dominiales quienes solo pueden ser afectados por poderes de policía administrativa general ${ }^{62}$.

Es que, en definitiva aun cuando estemos en presencia de un bien de titularidad pública, de lo que se trata no es que el Estado pueda ejercer una suerte de potestad "doméstica" sobre los particulares sino de regular el uso y explotación del bien, lo que supone, necesariamente, reconducir la cuestión al "poder de policía" y las consecuentes limitaciones que este puede imponer al ejercicio de los derechos privados, cuestión esta completamente indiferente a la titularidad, pública o privada, del bien que se trate63.

Así las cosas, la finalidad interventora que el Estado perseguiría por medio del régimen dominical podría ser lograda — de igual formatrasladando el eje del régimen de la noción de "propiedad" a la de "afectación" y, de allí, a su regulación por medio del poder de policía. Es precisamente el ejercicio de esta potestad pública — de base legislativa- la que permite, por un lado, garantizar la afectación de los bienes -en el caso, las infraestructuras públicas- a la satisfacción de los intereses

61 Así, Moysan, 2001, pp. 76 y ss. Según la Corte Suprema de Justicia argentina, la sujeción de la cosa al régimen de la "policía del dominio público" deriva de su propia afectación, cfr. CSJN, in re "Don Enrique Alió, por la Provincia de Buenos Aires v. Mar del Plata Golf Club sobre reivindicación", Fallos 146: 305.

62 En este sentido, Klein, 1966, pp. 274 y ss.

63 En este sentido, Fiorini, Bartolomé, "Los bienes de las concesiones de servicio público", en LL 154178, en especial, p. 180. La Corte Suprema argentina ha resuelto que la ejecución forzada de un bien privado afectado a la prestación de un servicio público no puede ser llevada a cabo sin con ello se afecta la continuidad del servicio, conf. in re "Ferrocarril Central Córdoba v. Ferrocarriles del Estado", Fallos 239: 349. Sobre esta cuestión, vid. Tawil, cit., pp. 531 y ss.; De la Riva, 2009, pp. 891 y ss. Por su parte, el Consejo Constitucional Francés ha aceptado que los bienes afectados a un servicio público pueden no pertenecer al dominio público, sin que por ello estos queden liberados del poder de control y regulación estatal, cfr. Decisión № 2005-513, del 14 de abril de 2005, la que puede consultarse en http://www.conseil-constitutionnel.fr/conseil-constitutionnel/francais/les-decisions/depuis1958/decisions-par-date/2005/2005-513-dc/decision-n-2005-513-dc-du-14-avril-2005.966.html. Sobre esta cuestión, vid. Fatome, 2006, pp. 178 y ss. 
públicos y, por otro, garantizar los derechos de terceros, sean los titulares o los usuarios de tales bienes e infraestructuras ${ }^{64}$. Se trata, así, de reconocer que esta clase de infraestructuras son "públicas" más que por su "titularidad", por su "destino" o "afectación", siendo esto último lo que verdaderamente justifica el poder de intervención estatal sobre las mismas.

Si bien por razones políticas o económicas (ej., casos de "bienes públicos" en sentido económico ${ }^{65}$ ) no cabe descartar la existencia infraestructuras sometidas al régimen dominial público, ésta se trata, solamente, de una alternativa meramente contingente y no consustancial con la actividad interventora estatal sobre la utilización y explotación de esta clase de bienes.

De esta forma, puede hacerse convivir la titularidad pública de infraestructuras que se estiman que serán mejor optimizadas si se permite que el Estado intervenga sobre ellas no solo a título de regulador sino ya, de dueño ${ }^{66}$, conjuntamente con aquellas en donde para permitir la maximización de los efectos sociales, políticos y económicos que se derivan de su explotación basta que exista la potestad pública de intervenir "externamente" sobre su operación ${ }^{67}$.

En definitiva, no se trata de reemplazar al régimen dominial por el poder de policía ni por la regulación, sino de afirmar que todos estos institutos pueden válidamente convivir entre sí e intercambiarse en su aplicación a diferentes bienes e infraestructuras según los también diferentes criterios, formas de financiamiento y finalidades públicas a las que se pretenda recurrir.

\section{Colofón}

64 Sobre los diferentes "modelos" de regulación, vid. lo que expusimos en Aguilar Valdez, 2006, pp. 121 y ss.

65 Se ha dicho que la "obligación del Estado es suministrar bienes públicos, es decir, bienes que provee la organización pública y cuyo precio son los impuestos que pagamos" (Sola, 2004, p. 320).

66 Se ha afirmado que la propiedad pública de esta clase de activos tiene sentido si el potencial ahorro de costos que produciría su titularización por el Sector Privado es pequeño, si los objetivos de interés público perseguidos con su explotación son de relevancia, si su contratación al Sector Privado es dificultosa y si los incentivos de los managers públicos para ahorrar costos no son demasiado débiles; cfr. Riess, 2005, p. 20-24.

67 Sobre el particular, vid. Olivi, cit., pp. 213 y ss. 
Se ha señalado que, en nuestra región, los requerimientos de inversión para cerrar la actual brecha de infraestructura son enormes, alcanzando el 6,2\% del PIB anual para el período 2012-2020 (unos 320.000 millones de dólares anuales del año 2012) ${ }^{68}$. Ello exige, con mayor rigor que nunca, poder buscar nuevos y originales mecanismos legales que permitan favorecer la afluencia de fondos para ser aplicados a una amplia gama de proyectos de infraestructura que permitan brindar los servicios públicos que nuestras sociedades reclaman. Y para ello, tanto la participación pública como la privada resultan imperiosas. Solo aguardamos que las reflexiones aquí volcadas permitan contribuir a esa solución.

\section{Referências}

Aguilar VALDEZ, Oscar R., "Consideraciones jurídicas sobre los principales modelos regulatorios: su visión desde la experiencia argentina", en Derecho \& Sociedad, № 26, Lima, 2006.

. "Contratos administrativos y financiamiento: La relación entre el financiamiento y los mecanismos de ejecución contractual. El caso de los Contratos de construcción y explotación de infraestructuras públicas", en Derecho \& Sociedad, № 29

ARIÑo \& AlmOGUERA ABOGADOS, Nuevo derecho de las infraestructuras, Montecorvo, Madrid, 2000.

BARCELONA LlOP, Javier, “Novedades en el régimen jurídico del dominio público en Francia”, en Revista de Administración Pública, № 137; Madrid, Mayo - Agosto. 1995 pp. 564 y ss.

BARRA, Rodolfo Carlos, Contrato de obra pública, Vol. I, Abaco, Buenos Aires, 1984, p. 68.

BoquÉ, Roberto, "Dominio público y derecho de retención (la tenencia como relación jurídica real de carácter administrativo)”, en Semanario Jurídico, T. 68, 1998-B, pp. 169 y ss.,

68 Conf. CEPAL, División de Recursos Naturales e Infraestructura, "La brecha de infraestructura económica y las inversiones en América Latina”, Boletín FAL, edición 332, 4/2014. 
Bourdié, Pedro Emilio v. Municipalidad de la Capital”, Fallos 145: 325El dominio fiduciario y los derechos reales administrativos. ¿Transmisión fiduciaria de las cosas del dominio público?", en Revista de Derecho Administrativo, № 61, Lexis Nexis, Buenos Aires, 2007, pp. 649 y ss.

CASSAGNE, Juan Carlos y DE LA Riva, Ignacio, "Formación, trayectoria y significado actual del dominio público en la Argentina”, en Revista de Derecho Administrativo, $\mathrm{n}^{\circ}$ 93, mayo-junio 2014, Abeledo Perrot, Buenos Aires, pp. 806-807.

CEPAL, División DE Recursos NATURALES E InFRAESTRUCTURA, "La brecha de infraestructura económica y las inversiones en América Latina”, Boletín FAL, edición $332,4 / 2014$.

Clavero Arévalo, Manuel, "La inalienabilidad del dominio público", en Clavero ARÉVALO, Manuel, Estudios de Derecho administrativo, Civitas, Madrid, 1992, p. 395 y las citas de doctrina que se invocan en p. 394.

COMADIRA, Julio Rodolfo, "La experiencia regulatoria argentina", en http://www.ElDial.com.ar.

De la CuÉtara Martínez, Juan Miguel, "Sobre las infraestructuras en red y competencia entre redes", en ARIÑo \& Almoguera ABogados (editores), Nuevo derecho de las infraestructuras, Montecorvo, Madrid, 2000, pp. 223 y ss.;

DE LA Riva, Ignacio, “El dominio público y los bienes afectados a la prestación del servicio público", en Comadira, Julio Pablo e IVANEGA, Miriam (coordinadores), Derecho administrativo. Libro en Homenaje al Profesor Julio Rodolfo Comadira, Ad Hoc, Buenos Aires, 2009, pp. 891 y ss.

De LaubadÉRe, André y Gaudemet, Yves, Traité de Droit Administratif, 11e ed, LGDJ, París, 1998, T. II (Droit Administratif de Biens), pp. 25, 45, 64 y ss.;

De Reina TARTí́Re, Gabriel [coord.], Dominio público. Naturaleza y régimen de bs bienes públicos, Heliasta, Buenos Aires, 2009, p. 125

DE REINA TARTIÉRE, Gabriel, "La teoría de los derechos reales administrativos: vigencia y aplicación en el derecho argentino", en El Derecho-Administrativo2006: 727 y ss.;

Debbasch, Charles; Bourdon, Jacques; Pontier, Jean Marie et Ricci, Jean Claude,

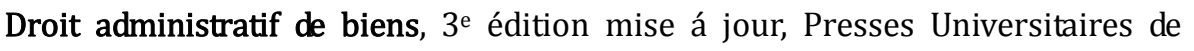
France, París, 1999, p. 108.

DownIE, Gordon and Mc Gregor, Laura, "Essential Facilities and Utilities Networks", en MAC GRegor, Laura; Prosser, Tony and Villiers, Charlotte, Regulation and Markets Beyond 2000, 
FANELLI EVANS, Guillermo, "La necesidad de recrear confianza y los derechos reales administrativos", en LL 2003-C-1263 y “

Las concesiones de obra y de servicios públicos y los derechos reales administrativos", en Revista de Derecho Administrativo, № 21/23, Depalma, Buenos Aires, 1996, pp. 93

FERNÁNDEZ ACEVEDo, Rafael, "Las concesiones demaniales en el tráfico jurídicoprivado", en DE REINA TARTIÉRE, Gabriel (coord.), Dominio público. Naturaleza y régimen de los bienes públicos, Heliasta, Buenos Aires, 2009, pp. 341 y ss.

FERNÁNDEZ DE VELAZCO, Recaredo, "Naturaleza jurídica del dominio público según Hauriou. Aplicación de su doctrina a la legislación española”, en Revista de Derecho Privado, № 8, Madrid, 1921, pp. 230 y ss.

FIORINI, Bartolomé, "Los bienes de las concesiones de servicio público", en LL 154-178, en especial, p. 180.

GARCÍA DE ENTERRÍA, Eduardo, "Sobre la imprescriptibilidad del dominio público", en GARCÍA DE EnTERRÍA, Eduardo, Dos estudios sobre la usucapión en derecho administrativo, 3aㅡ ed, Civitas, Madrid, 1998;

GARCía NovOA, César, Las amortizaciones en el impuesto sobre sociedades. Tratamiento jurídico tributario, Marcial Pons, Madrid, 1994, p. 123

GONZÁLEZ GARCíA, Julio V., "Dos cuestiones sobre compartición de infraestructuras de telecomunicaciones", en Revista de Administración Pública, № 153, Madrid, 2000 , pp. 351 y ss.

La titularidad de los bienes del dominio público, Marcial Pons, Madrid, 1998, pp. 39 y ss.;

GONZÁLEZ SANFIEL, Andrés M., Un nuevo régimen para las infraestructuras de dominio público, Montecorvo, Madrid, 2000, pp. 151 y ss.

GonZÁlEZ SANFIEL, Andrés, "Competencia en las infraestructuras demaniales y nuevo régimen para las infraestructuras de uso público", en ARIÑo \& ALMOGUERA ABOGADOS (editores), Nuevo derecho de las infraestructuras, Montecorvo, Madrid, 2000, pp. 182 y ss.;

GONZÁLEZ SANFIEL, Andrés, Un nuevo régimen para las infraestructuras de dominio público, Montecorvo, Madrid, 2000, pp. 243 y ss.

GoNZÁLEZ VARAS IBÁÑEZ, Santiago (dir), El derecho administrativo iberoamericano, Instituto Nacional de Administración Pública/Ministerio de Administraciones Públicas, Granada, 2005. 
GoRDiLlo, Agustín, "Obra pública y contrato de obra pública”, en Lecciones y Ensayos, № 32, Buenos Aires, 1966, p. 50.

Guiridlian LAROSA, Javier, "El Fideicomiso Público como técnica de financiación contractual administrativa", en ED-Administrativo- 2003-546.

., "La financiación en los contratos públicos y los derechos reales administrativos", en Revista de Derecho Administrativo, № 48, Lexis Nexis, Buenos Aires, 2004, pp. 338

Hauriou, Maurice. Préface" de Hauriou a la obra de Rigaud, Louis, La theorie de droits réels administratifs, Sirey, París, 1914, pp. v y ss.

., Précis de droit administratif et de droit public, $12^{\mathrm{a}}$ ed. revisada y puesta al día por André HAURIOU,

JimÉnEZ DE CiSnERos CID, Francisco, "Hacia un nuevo concepto de infraestructura pública / obra pública desligado del dominio público y del servicio público", cit., pp. 59 y ss.; 7

, Obras públicas e iniciativa privada, Montecorvo, Madrid, 1998, pp. 303 y SS.;

José Luis VILLAR PALASí. La intervención administrativa en la industria, Instituto de Estudios Políticos, Madrid, 1964, pp. 142 y ss.

LAUBADÉRE, André, Traité de Droit Administratif, sixiéme edition, LGDJ, París, 1975, T. II, p. 170.

LAVIALLE, Christian, "L'acte de gestion domaniale", en AA.VV., Mouvement du Droit Public. Mélanges en l’honneur de Franck Moderne, Dalloz, París, 2004, p. 279

LigniÉRES, Paul y RATLEDGE, Simon, "PPP in France - Healthcare Sector”, Linklaters Special Report, 1/10/2004.

Ligniéres, Paul, Partenariats Public-Privé, 2e ed., Lexis Nexis, París, 2005, pp. 249 y ss.

Lima, 2008 y en "La extinción anticipada de concesiones en materia de infraestructura y servicios públicos", en Revista de Derecho Administrativo, № 3, Círculo de Derecho Administrativo de la Pontificia Universidad Católica del Perú, Lima, 2007.

LIPSKY, Abbot and SIDAK, Gregory, "Essential Facilities”, en Standford Law Review, Vol. 51 , 1999, p. 1187; 
LÓPEZ DEL CARRIL, Gonzalo, "Motivos por los que no se pueden aplicar los derechos reales administrativos para generar confianza en los inversores", en LL 2003-F1486.

MAIRAL, Héctor, "Nuevas ideas en materia de dominio público", en AA.VV., Organización administrativa, función pública y dominio público. Jornadas organizadas por la Universidad Austral, Facultad de Derecho, RAP, Buenos Aires, 2005, pp. 131 y ss.

MALAGÓN, Jaime F., Fideicomiso y concesión. Ensayo sobre estructuras financiables para obras y servicios públicos en Latinoamérica, Porrúa, México, 2002.

MARCOU, Gérard, "La experiencia francesa de financiación privada de infraestructuras y equipamientos", en RuIz OJEDA, Alberto; MARCOU, Gérard y GoH, Jeffrey, La participación del sector privado en la financiación de infraestructuras y equipamientos públicos: Francia, Reino Unido y España (Elementos comparativos para un debate), Civitas, Madrid, 2000.

MARiEnhoff, Miguel S., Tratado de Derecho administrativo, $4^{\mathrm{a}}$ ed actualizada, Abeledo Perrot, Buenos Aires, 1994, Vol. III-B, pp. 514 y ss., y Vol. V, pp. 37 y 38;

MELLERAY, Fabrice, "L'Échelle de la Dominialité", en AA.VV., Mouvement du Droit Public. Mélanges en l'honneur de Franck Moderne, Dalloz, París, 2004, pp. 287 y SS.;

MERTEHIKIÁN, Eduardo, "Acerca de la utilización de fideicomisos por el sector público", en AA.VV., Organización administrativa, función pública y dominio público. Jornadas organizadas por la Universidad Austral, Facultad de Derecho, RAP, Buenos Aires, 2005, pp. 539 y ss

MoReu CARBonelL, Elisa, "Desmitificación, privatización y globalización de los bienes públicos: del dominio público a las obligaciones de dominio público", en Revista de Administración Pública, № 161, mayo-agosto, Madrid, 2003, pp. 435 y SS.;

Moysan, Hervé, Le Droit de Propieté des Persones Publiques, LGDJ, París, 2001, pp. 76 y ss.

OLIVI, Marco, Beni demaniali ad uso collectivo. Conferimento di funzioni e privatizzazione, Cedam, Padova, 2005, pp. 307 y ss.

Pablo Esteban, "La responsabilidad del Estado por riesgo", en AA.VV., Estudios de Derecho administrativo. XII Jornadas sobre Responsabilidad del Estado en Homenaje a Osvaldo Pritz, Diké-Foro de Cuyo, Mendoza, 2005, pp. 138 y ss. 
PARejo Alfonso, Luciano, "Dominio público: un intento de reconstrucción de su teoría general”, en Revista de Administración Pública, № 100-102, enerodiciembre, Madrid, 1983, pp. 2379 y ss.

Pitofsky, Robert; PATterson, Donna and Hooks, Johnattan, "Essential Facilities Doctrine Under U.S. Law”, en Antitrust Law Journal, Vol. 70, Chicago, 2002, p. 443;

RIESS, Armin, "Is the PPP model applicable across sectors?", en EUROPEAN INVESTMENT BANK, EIB Papers, Volume 10, N² 2, 2005, p. 20-24.

RIÑo \& AlMOGUERA ABOGAdos (editores), Nuevo derecho de las infraestructuras, Montecorvo, Madrid, 2000, pp. 38 y ss.;

RUIZ OJEDA, Alberto, Dominio Público y Financiación Privada de Infraestructuras y Equipamientos. Un estudio del caso francés y análisis comparativo de la reciente regulación española, ed. Marcial Pons, Madrid, 1999, p. 22 y ss.

SÁinz Moreno, Fernando, "El dominio público: una reflexión sobre su concepto y naturaleza, cincuenta años después de la fundación de la Revista de Administración Pública", en Revista de Administración Pública, № 150, septiembrediciembre, Madrid, 1999, p. 488.

SAlOMONI, "El régimen del dominio público en la República Argentina: Un intento de reconstrucción dogmática", en Actualidad en el Derecho Público, № 14, Buenos Aires, 2000, pp. 100 y ss., en especial, p. 102.

SALOMONI, Jorge Luis, "El régimen de los bienes públicos en las concesiones o licencias de servicios públicos en el ordenamiento jurídico argentino. El caso de la explotación de la distribución del gas natural", en AA.VV., El Derecho administrativo argentino hoy, Ciencias de la Administración, Buenos Aires, 1996, pp. 302 y ss.

Teoría general de los servicios públicos, Ad Hoc, Buenos Aires, 1999, pp. 359 y ss.

SAnTAmaría PASTor, Juan Alfonso, Principios de Derecho administrativo, Centro de Estudios Ramón Areces, Madrid, 1999, Vol. II, pp. 516 y 517.

SFEZ, Lucien, Essai sur la contribution du Doyen Hauriou au Droit administratif français, LGDJ, París, 1966, pp. 435 y ss.; y

SolA, Juan Vicente, Constitución y economía. Lexis Nexis, Buenos Aires, 2004, p. 320 
SUBRÁ DE BIEUSSES ("Dominio público y derechos reales", cit., p. 1179) "L'adaptation des contrats administratifs aux besoins d'investissement inmobilier sur le domaine public. Les aspects domaniaux des contrats de partenariat", en Actualité Juridique Droit Administratif, 21 mars 2005, pp. 591 y ss.

Subrá DE BIEUSSES, Pierre, "Dominio público y derechos reales”, en CASSAGNE, Juan Carlos (director) Derecho administrativo. Obra colectiva en Homenaje al Profesor Miguel S. Marienhoff, Abeledo Perrot, Buenos Aires, 1998, pp. 1167 y ss. (en especial, pp. 1177 y ss.)

TAWIL, Guido S., "Algunas reflexiones en torno al régimen jurídico de los bienes afectados al servicio público", en AA.VV., Organización administrativa, función pública y dominio público. Jornadas organizadas por la Universidad Austral, Facultad de Derecho, RAP, Buenos Aires, 2005, p. 536.

Tony and ViLLIERS, Charlotte, Regulation and Markets Beyond 2000, Ashgate, Aldershot (UK), 2000, p. 46, inter alia.

VILLAR EzCURRA, José Luis, "Las infraestructuras públicas: viejos y nuevos planteamientos", en ARiño \& Almoguera ABogados (editores), Nuevo derecho de las infraestructuras, Montecorvo, Madrid, 2000, pp. 71 y ss.;

VILLAR RoJAS, Francisco José, Las instalaciones esenciales para la competencia. Un estudio de derecho público económico, Comares, Granada, 2004.

WATRIN, Germain, "Quelques rapports entre les notions de Police, Domaine public et Service Public", en Revue de Droit Public et de la Science Politique en France et á l'etranger, LGDJ, París, 1936, pp. 147 y ss.

Recebido: 11/03/2015

Received: 03/11/2015

Aprovado: 12/03/2015

Approved: 03/12/2015 